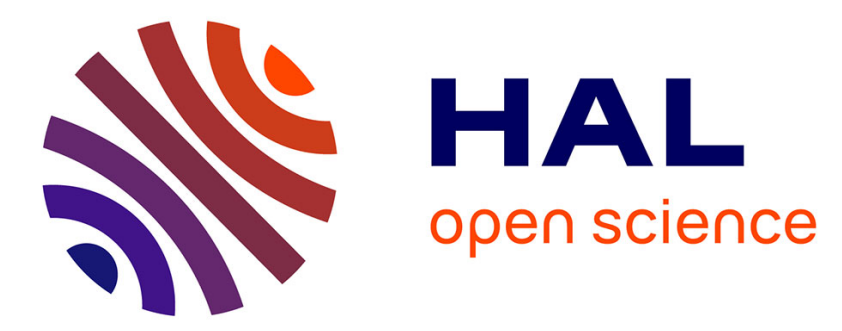

\title{
Microstructure and mechanical properties of a CoCrFeMnNi high entropy alloy processed by milling and spark plasma sintering
}

M. Laurent-Brocq, P.-A. Goujon, J. Monnier, B. Villeroy, L. Perrière, R. Pirès, G. Garcin

\section{To cite this version:}

M. Laurent-Brocq, P.-A. Goujon, J. Monnier, B. Villeroy, L. Perrière, et al.. Microstructure and mechanical properties of a $\mathrm{CoCrFeMnNi}$ high entropy alloy processed by milling and spark plasma sintering. Journal of Alloys and Compounds, 2019, 780, pp.856-865. 10.1016/j.jallcom.2018.11.181 . hal-02362220

\section{HAL Id: hal-02362220 \\ https://hal.science/hal-02362220}

Submitted on 27 Jul 2021

HAL is a multi-disciplinary open access archive for the deposit and dissemination of scientific research documents, whether they are published or not. The documents may come from teaching and research institutions in France or abroad, or from public or private research centers.
L'archive ouverte pluridisciplinaire HAL, est destinée au dépôt et à la diffusion de documents scientifiques de niveau recherche, publiés ou non, émanant des établissements d'enseignement et de recherche français ou étrangers, des laboratoires publics ou privés. 


\title{
Microstructure and mechanical properties of a CoCrFeMnNi high entropy alloy processed by milling and spark plasma sintering.
}

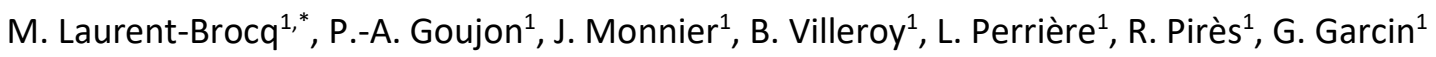 \\ ${ }^{1}$ Université Paris Est, ICMPE (UMR 7182), CNRS, UPEC, F- 94320 THIAIS France \\ *Corresponding author : laurent-brocq@icmpe.cnrs.fr
}

\begin{abstract}
Powder metallurgy is a promising processing path to produce high entropy alloys (HEA) with improved mechanical properties. According to this, a bulk CoCrFeMnNi alloy was milled with a wide range of conditions. It was shown that a powder which is micronic, approximately spherical and with nanometric crystallites could be produced by a cryo-milling which was followed by a short duration planetary milling. Next, this powder was fully densified by spark plasma sintering. According to $\mathrm{X}$-ray diffraction, the single phase of the bulk alloy remains stable during both milling and sintering. However, carbides and oxides precipitate during sintering, as shown by scanning electron microscopy coupled with energy dispersive spectroscopy. Electron backscattered diffraction evidence that those precipitates limit the growth of grains. By nanoindentation measurements, it was shown that preparing a CoCrFeMnNi HEA by milling and sintering significantly increases the hardness compared to conventional processing by melting and casting. Moreover, the different strengthening contributions were calculated and analyzed. It revealed that grains have a strengthening contribution as described by the Hall \& Petch law, contrary to crystallites.
\end{abstract}

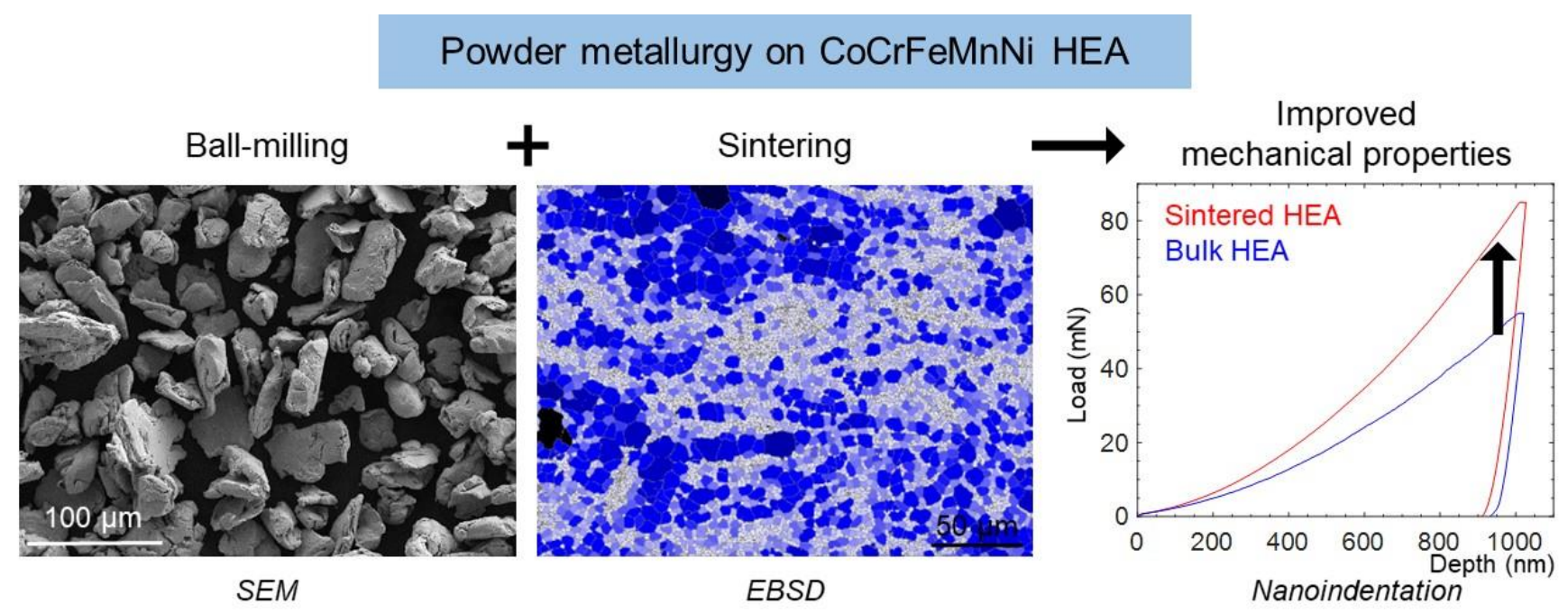

Figure : graphical abstract 


\section{Keywords}

Metals and alloys; nanostructured materials; powder metallurgy; sintering; microstructure; grain boundaries; mechanical properties.

\section{Highlights}

- A micronic and nearly spherical CoCrFeMnNi powder is produced by a two-step milling

- This powder is fully densified by spark plasma sintering

- The single phase of the bulk alloy remains stable during milling and sintering

- Carbides and oxides limit the growth of grains

- Grains are strengthening, contrary to crystallites 


\section{Introduction}

Since their discovery in 2004 [1, 2], high entropy alloys (HEA) have aroused an increasing interest. HEA are multicomponent alloys in which every component is very concentrated, or, in other words, in which the distinction between solvent and solute does not exist anymore. At first, studies focused on HEA compositions which were single-phased (ie : one solid solution), such as the quinary equimolar CoCrFeMnNi [3], also known as the Cantor alloy. Those single-phased HEA have the advantage to be thermodynamically stable at high temperature $[4,5]$. Moreover, they exhibit an unprecedented combination of mechanical strength and ductility [6]. This is the case for example for the CoCrFeMnNi alloy whose yield strength and toughness at $293 \mathrm{~K}$ are respectively $500 \mathrm{MPa}$ and $200 \mathrm{MPa} \cdot \mathrm{m}^{-1 / 2}$ [7]. A high yield strength was indeed expected due to the strengthening of this unusual multicomponent solid-solution [8]. However, for very demanding applications, an even higher yield strength is required. That's why lately additional strengthening mechanisms have been explored and applied to HEA, such as precipitation hardening $[9,10]$, transformation and twinning induced plasticity (TRIP and TWIP) [11, 12] or grain size decrease [13].

To begin, HEA were mainly processed by conventional melting, casting and thermomechanical treatments [14-16]. To further improve the properties, including the mechanical ones, new processing routes are now tested like the high pressure torsion [17] or swaging [18] in order to heavily deform alloys. Powder metallurgy is another alternative and promising processing route. Indeed, it can produce complex shapes and/or nanocrystalline alloys which can exhibit advantageous mechanical properties. Powder metallurgy has already been applied for various HEA systems [19-23] and ball-milling, which is a simple technique, was often used to produce powders. Most of the time, the alloy was formed via mechanical alloying (ie: using pure metals as starting materials) and complex, multiphased and sometimes metastable microstructures were formed. For example, milling $\mathrm{Co}, \mathrm{Cr}, \mathrm{Fe}, \mathrm{Mn}$ and $\mathrm{Ni}$ powders in equiatomic proportion leads to the formation of several phases (fcc, bcc, $\sigma$, amorphous) [24-26], although a single fcc phase is thermodynamically predicted for this composition [5]. Sometimes, new phases are formed, or some phases disappear during subsequent sintering $[24,26,27]$. Thus, the capacity of ball-milling to produce metastable phases, which is often desired, becomes a drawback for HEA for which the stable phases are the ones of interest. For this study, ball-milling, which is a simple and not expensive technique, was selected to produce HEA powder. To avoid the formation of metastable unwanted phases, it was chosen to prepare the alloy by melting and casting and afterwards to produce powder by milling. Spark Plasma Sintering (SPS) was chosen to densify the HEA powders because of its capacity to quickly heat samples, which usually limits grain growth.

The aim of this study is to contribute to assess the potential of powder metallurgy to produce HEA with improved mechanical properties. The equimolar CoCrFeMnNi composition was selected as a test case because it has already been widely studied as a bulk material. The objectives are: (i) to determine the processing conditions to produce a HEA powder and to fully densify it; (ii) to characterize the obtained microstructure and (iii) to compare the mechanical properties to a bulk HEA. First, a wide range of milling conditions were tested and the obtained powders were characterized, with a focus on the evolution of crystallite size and of granulometry. Second, the most satisfying HEA powder was sintered by SPS and was deeply characterized by X-Ray Diffraction (XRD), Scanning Electron Microscopy (SEM) coupled with Energy Dispersive X-ray Spectroscopy (EDS) and Electron BackScattered Diffraction (EBSD). Third, the hardness of the sintered HEA was locally measured by nanoindentation. Finally, the contribution of the different strengthening mechanism was discussed.

\section{Material and methods}

The equimolar Cantor alloy CoCrFeMnNi was produced from bulk raw $\mathrm{Co}, \mathrm{Cr}$, Fe, $\mathrm{Mn}$ and $\mathrm{Ni}$ (purity > 99.9 wt.\%). First, raw elements were melted by high frequency electromagnetic induction in a water-cooled copper crucible. Then gravity casting was performed to shape the ingots. One ingot was homogenized at $1373 \mathrm{~K}$ for 6 days under an Ar atmosphere. Those processing conditions are detailed in [5]. The processing path of this bulk homogenized sample is common for HEA and thus this sample serves as a reference. Another ingot was re-melted and quenched 
using melt spinning in order to shape the ingot into a thin ribbon. The cooling rate was in the range $10^{5}-10^{6} \mathrm{~K} \cdot \mathrm{s}^{-1}$. The obtained ribbon has a thickness between 30 and $50 \mu \mathrm{m}$ and a length of around $1 \mathrm{~m}$. The milling was performed on small pieces of ribbon (with a length of few millimeters), with two different types of equipment. The first one is a planetary Fritsch $\mathrm{P7}$ premium with a $80 \mathrm{~mL}$ vial. A powder to ball ratio (BPR) of $1 / 15$ was used, with steel balls with a diameter of $7 \mathrm{~mm}$ and a speed of 600 rotation per minute $(\mathrm{rpm})$. The second one is a linear Retsch Cryomill which grinds at $77 \mathrm{~K}$ by impact and friction at a vibrating frequency of $20 \mathrm{~Hz}$. The BPR was $1 / 8$ with steel balls with a diameter of $12 \mathrm{~mm}$. For both types of equipment, the vials were sealed under an argon atmosphere. The sintering equipment was the Fuji 515S Spark Plasma Sintering (SPS) equipment of the "Plateforme lle-de-France de Frittage". Graphite mold lined with graphite paper with a diameter of $8 \mathrm{~mm}$ was used. Sintering was performed under vacuum. The applied temperature and pressure cycles are given in Fig. 1. The temperature was increased up to a maximum temperature $\mathrm{T}_{\max }$ of $850^{\circ} \mathrm{C}$ with a heating speed of $100{ }^{\circ} \mathrm{C} \cdot \mathrm{min}^{-1}$. Once $\mathrm{T}_{\max }$ was reached, a uniaxial pressure of $100 \mathrm{MPa}$ was applied to the pellet. Both the maximum temperature and the pressure were maintained during 4 min. Afterwards, load and temperature were decreased in a few minutes.

All the samples which are presented in this study are listed in Table 1. They are named HEA-x where $x$ is either $b, r$, $\mathrm{m}$ or $\mathrm{s}$ for bulk, ribbon, milled powder or sintered pellet respectively. For milled powders, additional information is added to the name to describe the milling conditions: $C$ and $P$ respectively stand for cryogenic and planetary milling while the number is for the duration of milling in hour. For example, HEA-m-C0.5 corresponds to a milled powder which was obtained by a cryogenic milling during $0.5 \mathrm{~h}$.

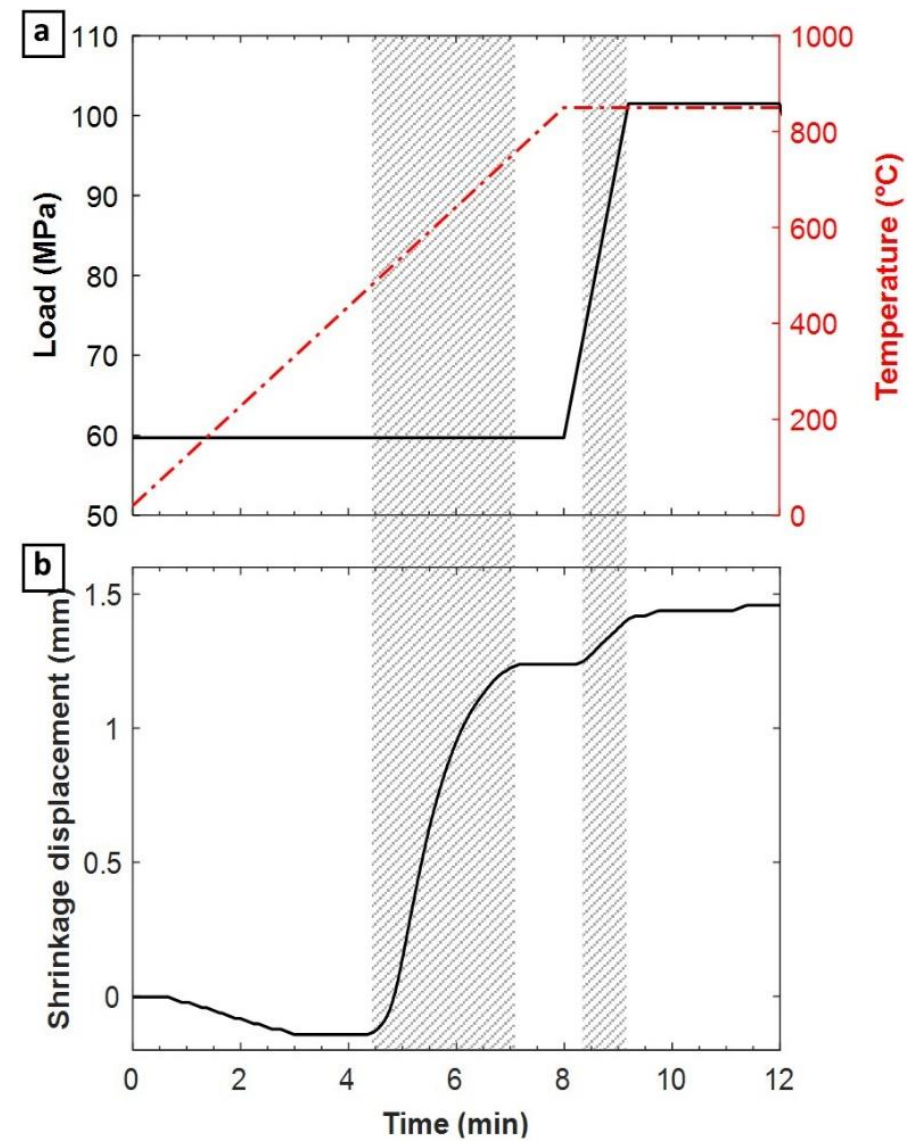

Fig. 1 (Color online): (a) Temperature (red dot line) and pressure (black straight line) applied during the SPS process to obtain the sintered HEA-s. (b) The shrinkage displacement (i.e. the relative displacement of the punch) is also plotted. The grey dashed areas indicate the large increase of the shrinkage displacement.

Table 1 : List of the samples. The processing conditions and some of the characterization results are also listed.

\begin{tabular}{l|l} 
Name & Processing
\end{tabular}




\begin{tabular}{|c|c|c|c|c|c|}
\hline & $\begin{array}{l}\text { Starting } \\
\text { material }\end{array}$ & Conditions & Phases & $\begin{array}{l}\text { Lattice } \\
\text { parameter }(\mathrm{nm})\end{array}$ & $\begin{array}{l}\text { Crystallite size } \\
(\mathrm{nm})\end{array}$ \\
\hline HEA-b & $\begin{array}{l}\text { Raw } \mathrm{Co}, \mathrm{Cr} \\
\mathrm{Fe}, \mathrm{Mn}, \mathrm{Ni}\end{array}$ & $\begin{array}{l}\text { Induction melting, suction } \\
\text { casting and homogenization } \\
\text { annealing }\end{array}$ & fcc & $0.3603 \pm 0.003$ & $48 \pm 34$ \\
\hline HEA-r & $\begin{array}{l}\text { Raw Co, Cr, } \\
\mathrm{Fe}, \mathrm{Mn}, \mathrm{Ni}\end{array}$ & $\begin{array}{l}\text { Induction melting and melt- } \\
\text { spinning }\end{array}$ & fcc & $0.3599 \pm 0.0002$ & $117 \pm 28$ \\
\hline
\end{tabular}

\begin{tabular}{|c|c|c|c|c|c|c|}
\hline \multicolumn{2}{|c|}{ HEA milled powders } \\
\hline \multirow{2}{*}{ Name } & \multicolumn{3}{|c|}{ Processing } & \multicolumn{3}{c|}{ Characterization } \\
\cline { 2 - 7 } & $\begin{array}{c}\text { Starting } \\
\text { material }\end{array}$ & Miller & Duration $(\mathrm{h})$ & Phases & $\begin{array}{c}\text { Lattice } \\
\text { parameter }(\mathrm{nm})\end{array}$ & $\begin{array}{c}\text { Crystallite size } \\
(\mathrm{nm})\end{array}$ \\
\hline HEA-m-P1 & HEA-r & Planetary & 1 & $\mathrm{fcc}$ & $-*$ & $-^{*}$ \\
\hline HEA-m-P2 & HEA-r & Planetary & 2 & $\mathrm{fcc}$ & $-*$ & $-^{*}$ \\
\hline HEA-m-C0.5 & HEA-r & Cryo & 0,5 & $\mathrm{fcc}$ & $0.3595 \pm 0.0003$ & $12 \pm 3$ \\
\hline HEA-m-C1 & HEA-r & Cryo & 1 & $\mathrm{fcc}$ & $0.3597 \pm 0.0004$ & $11 \pm 3$ \\
\hline HEA-m-C2 & HEA-r & Cryo & 2 & $\mathrm{fcc}$ & $0.3597 \pm 0.0005$ & $12 \pm 5$ \\
\hline HEA-m-CP & HEA-m-C1 & Planetary & 0,5 & $\mathrm{fcc}$ & $0.3597 \pm 0.0004$ & $12 \pm 5$ \\
\hline
\end{tabular}

\begin{tabular}{|c|c|c|c|c|c|}
\hline \multicolumn{2}{|c|}{ HEA sintered pellets } \\
\cline { 2 - 6 } & $\begin{array}{c}\text { Starting } \\
\text { material }\end{array}$ & Conditions & Phases & $\begin{array}{c}\text { Lattice } \\
\text { parameter }(\mathrm{nm})\end{array}$ & $\begin{array}{c}\text { Crystallite size } \\
(\mathrm{nm})\end{array}$ \\
\hline \multirow{2}{*}{ HEA-s } & HEA-m-CP & $\begin{array}{c}\text { SPS: graphite mold, } \\
\text { Tmax }=850^{\circ} \mathrm{C}, \mathrm{P}=100 \mathrm{Mpa}\end{array}$ & $\begin{array}{c}\mathrm{fcc}+\mathrm{Cr} \\
\text { carbide }+\mathrm{Mn} \\
\text { oxide }\end{array}$ & $0.3608 \pm 0.0003$ & $32 \pm 13$ \\
\hline
\end{tabular}

* Because of very large powder grains, XRD characterization and thus lattice parameter and crystallite size computation were not possible.

\begin{tabular}{|c|c|c|c|c|c|}
\hline \multicolumn{9}{|c|}{ HEA ribbon } \\
\hline \multirow{3}{*}{ Name } & \multicolumn{3}{|c|}{ Processing } & Characterization \\
\cline { 2 - 6 } & $\begin{array}{c}\text { Starting } \\
\text { material }\end{array}$ & Conditions & $\begin{array}{c}\text { Lattice } \\
\text { parameter }(\mathrm{nm})\end{array}$ & $\begin{array}{c}\text { Crystallite size } \\
(\mathrm{nm})\end{array}$ \\
\hline \multirow{3}{*}{ HEA-r } & $\begin{array}{c}\text { Raw Co, Cr, } \\
\text { Fe, Mn, Ni }\end{array}$ & $\begin{array}{c}\text { Induction melting and melt- } \\
\text { spinning }\end{array}$ & $\mathrm{fcc}$ & $\begin{array}{c}0,3599+/- \\
0,0002\end{array}$ & $117+/-28$ \\
\hline
\end{tabular}

\begin{tabular}{|c|c|c|c|c|c|c|}
\hline \multicolumn{2}{|c|}{ Processing } & \multicolumn{3}{c|}{ Characterization } \\
\cline { 2 - 7 } Name & $\begin{array}{c}\text { Starting } \\
\text { material }\end{array}$ & Miller & Duration (h) & Phases & $\begin{array}{c}\text { Lattice } \\
\text { parameter }(\mathrm{nm})\end{array}$ & $\begin{array}{c}\text { Crystallite size } \\
(\mathrm{nm})\end{array}$ \\
\hline HEA-m-P1 & HEA-r & Planetary & 1 & $\mathrm{fcc}$ & $-*$ & $-*$ \\
\hline HEA-m-P2 & HEA-r & Planetary & 2 & $\mathrm{fcc}$ & $-*$ & $-^{*}$ \\
\hline HEA-m-C0,5 & HEA-r & Cryo & 0,5 & fcc & $\begin{array}{c}0,3595+/- \\
0,0003\end{array}$ & $12+/-3$ \\
\hline HEA-m-C1 & HEA-r & Cryo & 1 & fcc & $\begin{array}{c}0,3597+/- \\
0,0004\end{array}$ & $11+/-3$ \\
\hline
\end{tabular}




\begin{tabular}{|c|c|c|c|c|c|c|} 
HEA-m-C2 & HEA-r & Cryo & 2 & fcc & $\begin{array}{c}0,3597+/- \\
0,0005\end{array}$ & $12+/-5$ \\
\hline HEA-m-CP & HEA-m-C1 & Planetary & 0,5 & fcc & $\begin{array}{c}0,3597+/- \\
0,0004\end{array}$ & $12+/-5$ \\
\hline
\end{tabular}

\begin{tabular}{|c|c|c|c|c|c|}
\hline \multicolumn{5}{|c|}{ HEA sintered pellets } \\
\hline \multirow{3}{*}{ Name } & \multicolumn{3}{|c|}{ Processing } & \multicolumn{3}{c|}{ Characterization } \\
\cline { 2 - 6 } & $\begin{array}{c}\text { Starting } \\
\text { material }\end{array}$ & Conditions & Phases & $\begin{array}{c}\text { Lattice } \\
\text { parameter }(\mathrm{nm})\end{array}$ & $\begin{array}{c}\text { Crystallite size } \\
(\mathrm{nm})\end{array}$ \\
\hline \multirow{3}{*}{ HEA-s } & HEA-m-CP & $\begin{array}{c}\mathrm{SPS}: \text { graphite mold, } \\
\text { Tmax }=850^{\circ} \mathrm{C}, \mathrm{P}=100 \mathrm{Mpa}\end{array}$ & $\begin{array}{c}\mathrm{fcc}+\mathrm{Cr} \\
\text { carbide }+\mathrm{Mn} \\
\text { oxide }\end{array}$ & $\begin{array}{c}0,3608+/- \\
0,0003\end{array}$ & $32+/ 13$ \\
\hline
\end{tabular}

At each step of the processing, the samples were characterized by X-Ray Diffraction (XRD) on a PANAlytical X'Pert Pro diffractometer using the Co-K $\alpha$ radiation at a wavelength of $0.178897 \mathrm{~nm}$. For each pattern, the four diffracting peaks were fitted by a pseudo-Voigt function and the instrumental width, which was measured on a LaB $_{6}$ reference sample, was subtracted. The lattice parameter and the crystallite size of the face-centered cubic phase were calculated using respectively the Bragg and Scherrer formula. The given values and uncertainties correspond to the average and standard deviation calculated from the data of the four peaks. Elemental, morphological and microstructural characterizations were performed using a Zeiss Merlin Field Emission Scanning Electron Microscope (FE-SEM) coupled with an Energy Dispersive X-ray Spectrometer (EDS) and an Electron BackScattered Diffraction detector (EBSD) from Oxford Instruments. Both detectors are driven by AZtec operating system. To investigate the crystallographic orientations by EBSD, a step size of $0.2 \mu \mathrm{m}$ was chosen to map an area of around $4.10^{4} \mu \mathrm{m}^{2}$. Some samples were characterized with a Zeiss Axio optical microscope, which is coupled with an integrated camera. The density of the pellet was also measured using the Archimedean method.

Finally, a nanoindenter equipped with a Berkovich tip was used. For the HEA-s sample, thanks to optical observations within the nanoindenter, indents were positioned in areas with or without precipitates (which correspond to areas with respectively small or large grains). To obtain a similar indentation size effect and, thus comparable hardness, indents were performed with a constant depth of $1 \mu \mathrm{m}$. This corresponds to a maximum applied load of 55, 70 and $85 \mathrm{mN}$ for respectively HEA-b, HEA-r in area with large grains and HEA-r in area with small grains. The hardness was determined using the Oliver and Pharr model [28]. The reported hardness $\mathrm{H}_{1 \mu m}$ and the corresponding uncertainty (Table 3 ) are respectively the average and standard deviation of the 20 measurements performed for each sample. Moreover, around 50 indentations with depths varying between 0.5 and $5 \mu \mathrm{m}$ were performed for each sample. Those measurements were fitted on the Nix and Gao model [29] to deduce the hardness at an infinite depth $\mathrm{H}_{0}$, for which there is no size effect (Table 3). The given uncertainty of $\mathrm{H}_{0}$ corresponds to the fit uncertainty.

\section{Results}

\subsection{Milling of a bulk HEA}

At first, the bulk CoCrFeMnNi ribbon (HEA-r) obtained by induction melting and melt-spinning was characterized by XRD. It was checked that the alloy was composed of a single face-centered cubic ( $\mathrm{fcc}$ ) solid solution, with a lattice parameter of 0,3599 $\pm 0,0002 \mathrm{~nm}$. This is in very good agreement with previous results on bulk CoCrFeMnNi $[3,30]$. Moreover, a crystallite size of $117 \pm 28 \mathrm{~nm}$ was determined. This sub-micronic crystallite size was very likely induced by the fast cooling rate during melt-spinning.

Afterwards, planetary milling, which is a simple technique, was tested to produce CoCrFeMnNi powder. Small pieces of the bulk CoCrFeMnNi ribbon were milled during 1 and $2 \mathrm{~h}$. The morphology and grain size of the obtained 
powder, which were named respectively HEA-m-P1 and HEA-m-P2, were characterized by optical microscopy and are presented on Fig. 2 and Table 2. After $1 \mathrm{~h}$ of planetary milling, slightly anisotropic and roughly spherical powder grains are formed. Their size is approximately $800 \mu \mathrm{m}$. Unexpectedly, after $2 \mathrm{~h}$ of planetary milling, the powder grain size increases up to millimetric values and most of the powder grains are welded to the miller vial. Since a serious damaging of the vial was induced without obtaining a satisfying powder grain size, planetary milling was given up and no further characterizations were performed on HEA-m-P1 and HEA-m-P2. Instead, cryogenic milling, which is usually used in powder metallurgy to favor the fracture of powder grain, was tested. Small pieces of the CoCrFeMnNi ribbon were cryo-milled during $0.5,1$ and $2 \mathrm{~h}$. The corresponding samples were named respectively HEA-m-C0.5, HEA-m-C1 and HEA-m-C2. The evolution of powder grain shape was followed by SEM (Fig. 3a, b, c and $\left.c^{\prime}\right)$. When increasing the milling time, powder grains become finer. More specifically, they become more and more anisotropic and can be qualified as "flakes". This is evidenced on Fig. 3c' for which the sample was tilted inside the SEM. More quantitatively, at the beginning of cryo-milling, powder grain size is very dispersed and ranges from 10 up to $3000 \mu \mathrm{m}$ and 5 to $500 \mu \mathrm{m}$ after respectively 0.5 and $1 \mathrm{~h}$ of cryo-milling (Table 2). After $2 \mathrm{~h}$ of cryo-milling, powder grains have an average size of $22 \pm 8 \mu \mathrm{m}$. Their width decreases from $2.5 \mu \mathrm{m}$ for HEA-m-C0.5 down to 0.3 $\mu \mathrm{m}$ for HEA-m-C2. Compared to planetary milling, cryogenic milling has the advantage to limit the sticking and welding of powder grains on the vial as well as to efficiently decrease their size.

Since the starting pieces of ribbon were also very anisotropic (length of few millimeters and width between 30 and $50 \mu \mathrm{m}$ ), more isotropic HEA starting materials were also cryo-milled (i.e.: shavings and large round pieces obtained respectively by filing and sawing the HEA ingots). Similar flake powder grains were formed (results not shown here). Consequently, the shape of the starting material does not influence the final shape of powder grains after cryomilling.

Some cryo-milled HEA powders were sintered by SPS. However, a too large volume fraction of porosity ( $>4 \%$ ) was obtained. To obtain a powder which is more appropriate for sintering, it was decided to perform a two-step milling: (1) a cryogenic milling in order to decrease the size of powder grains followed by (2) a planetary milling in order to round them. More precisely, based on the previous results, a cryogenic milling with a duration of $1 \mathrm{~h}$ was considered as a good compromise to decrease powder grain length and to limit the width thinning. Planetary milling lasts only for $0.5 \mathrm{~h}$ to avoid the welding of powder grains on the vial. The sample HEA-m-CP was produced through this twostep milling. Powder grains have an average length and width of respectively $80 \pm 30 \mu \mathrm{m}$ and $20 \pm 8 \mu \mathrm{m}$ (Table 2). Compared to HEA-m-C1, the average size and the dispersion of size distribution decrease while the width increases. This was obtained through the folding of the flakes which were formed during the previous cryogenic milling (Fig. $\left.3 d^{\prime}\right)$.

The milled powders were also characterized by XRD (Fig. 4). As for the bulk ribbon, all the milled powders are composed of a single fcc phase. In other words, no secondary undesired phases were formed during milling. The lattice parameter is similar to the one of the bulk ribbon for all powders (Table 1). The crystallite size decreases from $117 \pm 28 \mathrm{~nm}$ down to $12 \pm 3 \mathrm{~nm}$ during the first $0.5 \mathrm{~h}$ of cryogenic milling. For longer milling time, the crystallite size remains stable. Thus, crystallite size is very efficiently decreased by milling.

To summarize, a two-step ball-milling (i.e.: $1 \mathrm{~h}$ of cryogenic milling followed by $0.5 \mathrm{~h}$ of planetary milling) was performed. The obtained powder grains are approximately spherical, their size is micronic, they are composed of a single fcc solid solution and their crystallite size is nanometric $(12 \pm 5 \mathrm{~nm})$. They are consequently considered as satisfying for sintering.

Table 2 : Powder grain sizes of milled HEA which were measured on optical images for HEA-m-P1 and HEA-m-P2 or on SEM images for the other samples.

\begin{tabular}{|c|c|c|}
\hline Name & Length $(\boldsymbol{\mu m})$ & Width $(\boldsymbol{\mu m})$ \\
\hline HEA-m-P1 & $800 \pm 100$ & $-{ }^{\text {a }}$ \\
\hline HEA-m-P2 & $1000 \pm 250$ & $-{ }^{\text {a }}$ \\
\hline HEA-m-C0.5 & $10-3000^{\mathrm{b}}$ & $2.5 \pm 0.5$ \\
\hline
\end{tabular}




\begin{tabular}{|c|c|c|} 
HEA-m-C1 & $5-500^{\mathrm{b}}$ & $1.1 \pm 0.4$ \\
\hline HEA-m-C2 & $22 \pm 8$ & $0.3 \pm 0.1$ \\
\hline HEA-m-CP & $80 \pm 30$ & $20 \pm 8$ \\
\hline
\end{tabular}

${ }^{a}$ A powder grain width was not defined because grains were only slightly anisotropic.

${ }^{\mathrm{b}}$ Minimum and maximum lengths are given because powder grain size distribution is very large
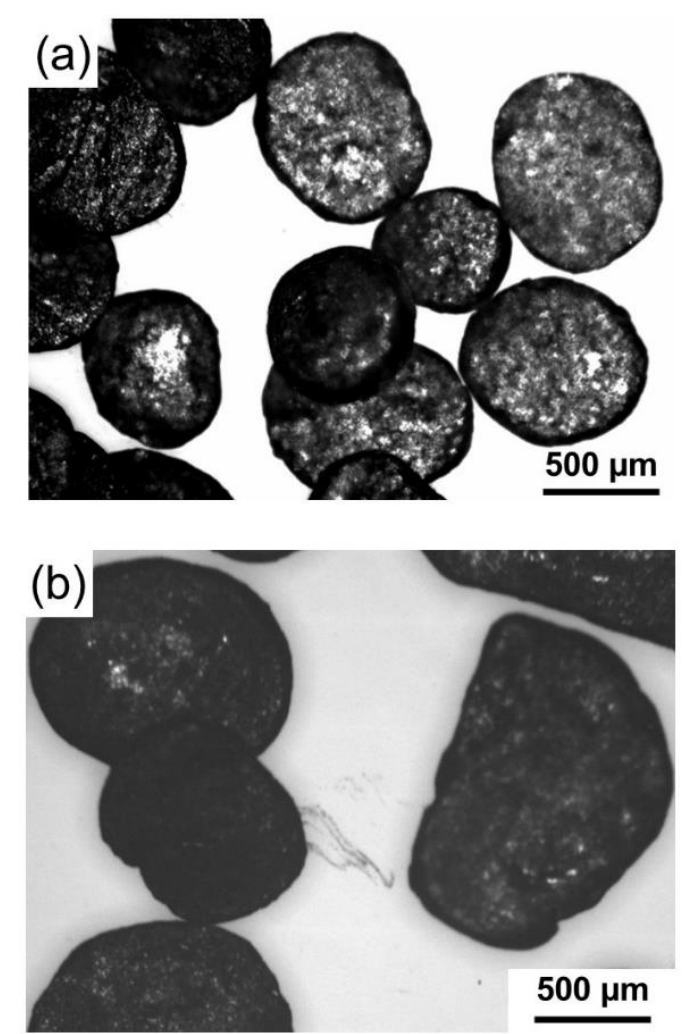

Fig. 2 : Optical microscope images of the CoCrFeMnNi HEA powders which were obtained by planetary ball-milling at ambient temperature during (a) $1 \mathrm{~h}$ (HEA-m-P1) and (b) 2 h (HEA-m-P2). 

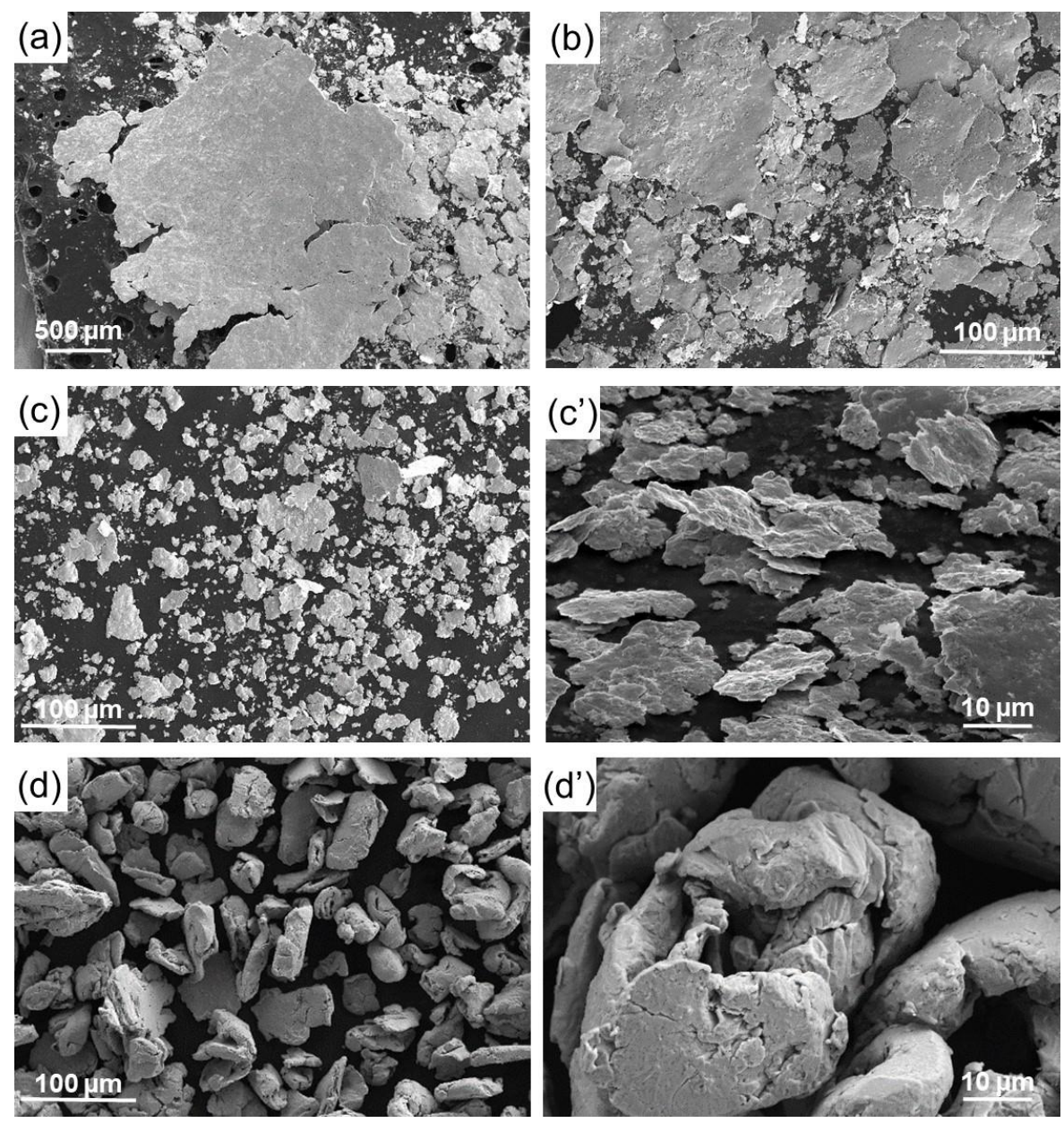

Fig. 3 : Scanning electron microscope images of the CoCrFeMnNi HEA powders. First, powders were obtained by cryogenic ball-milling during (a) 0.5h (HEA-m-CO.5), (b) $1 \mathrm{~h}$ (HEA-m-C1), (c) and ( $\left.c^{\prime}\right) 2 \mathrm{~h}$ (HEA-m-C2). ( $\left.c^{\prime}\right)$ is a tilted zoom of (c). Second, HEA powders were produced by a two-steps milling: (d) and ( $\left.d^{\prime}\right) 1 \mathrm{~h}$ cryogenic ball-milling which was followed by a $0.5 \mathrm{~h}$ planetary ball-milling at room temperature (HEA-m-CP). (d') is a zoom of $(d)$. 

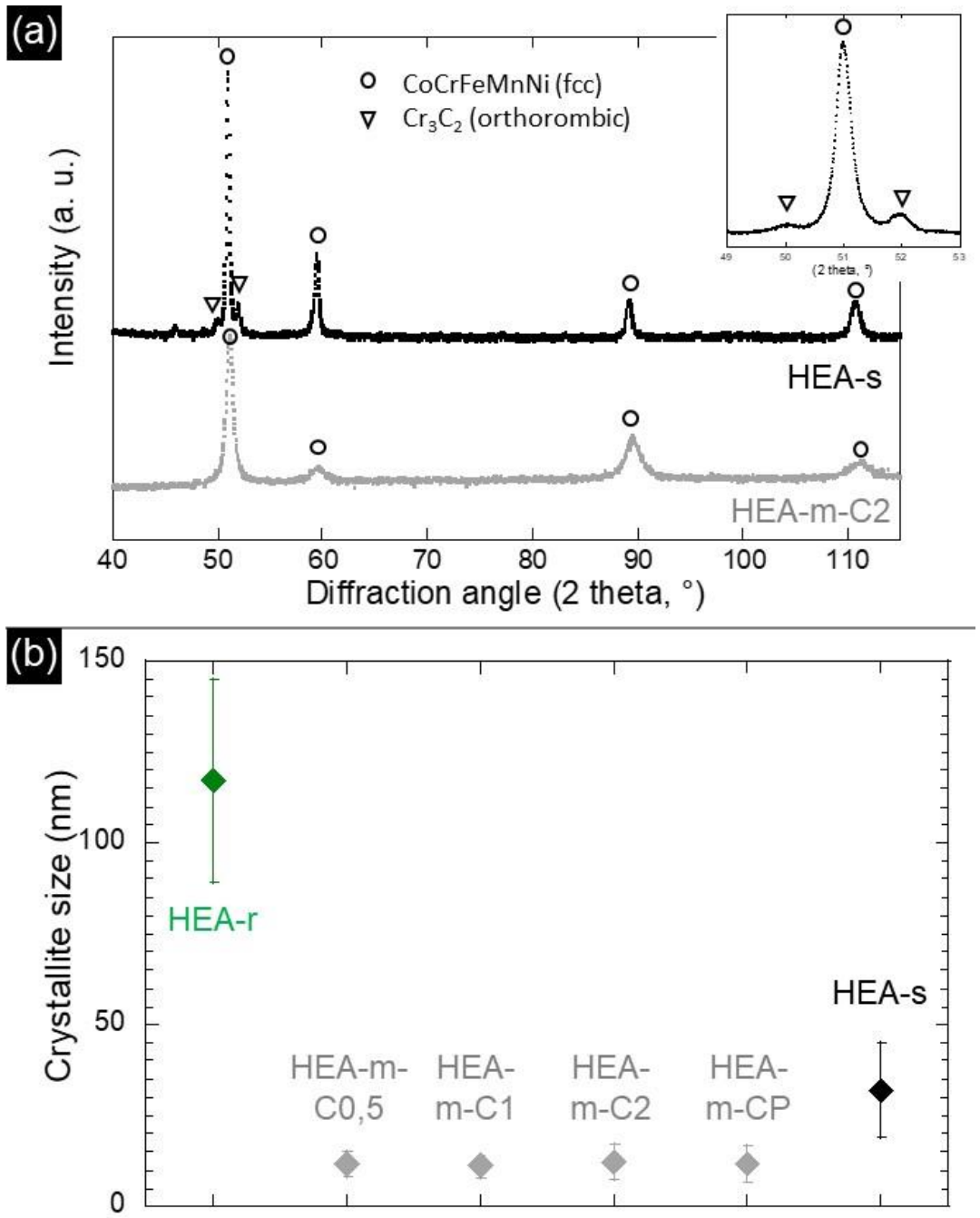

Fig. 4 (Color online): X-ray diffraction analysis. (a) XRD patterns of HEA powders after $2 \mathrm{~h}$ of cryogenic ball-milling (HEA-m-C2, gray) and of SPS densified HEA (HEA-s, black). The top-right inset is a zoom of HEA-s XRD pattern. Dots and triangles indicate the diffraction angles of respectively a $\mathrm{Cr}_{3} \mathrm{C}_{2}$ orthorhombic chromium carbide and of the face centered cubic CoCrFeMnNi solid solution. (b) Average crystallite size of CoCrFeMnNi after melt-spinning (HEA-r); after cryogenic ball-milling of 0.5, 1 and 2 h (HEA-m-CO.5; HEA-m-C1; HEA-m-C2); after cryo and planetary milling (HEA-m-CP); after SPS (HEA-s).

\subsection{Sintering of the HEA powder}

The HEA-m-CP powder, which was obtained through the two-step milling, was sintered by SPS. After preliminary tests and based on previous results from the literature [24,31], it was chosen to apply during 4 minutes a maximum load and temperature of respectively $100 \mathrm{MPa}$ and $850^{\circ} \mathrm{C}$ (Fig. 1a). There is a significant increase of the shrinkage displacement during the increase of temperature, more precisely between 475 and $760{ }^{\circ} \mathrm{C}$ (large grey area on Fig. 1b). It is due to the sintering of the sample. A second increase of the shrinkage displacement takes place when the pressure is applied. It could be due to a plastic deformation of the pellet, or an increase of it, or to the very end of sintering. The sintered sample was named HEA-s. The measured volume fraction of porosity was $0.9 \%$. This very low value indicates that the chosen SPS conditions allow to reach a full sintering.

The XRD pattern of the HEA-s pellet reveals the presence of two phases (Fig. 4a). The first one is the fcc solidsolution, which was the only phase in the powder before sintering. Compared to the HEA-m-CP powder, the lattice parameter remains the same while the crystallite size slightly increases from $12 \pm 5 \mathrm{~nm}$ to $32 \pm 13 \mathrm{~nm}$ (Fig. $4 \mathrm{~b}$ and Table 1). A crystallite growth is expected during the heating of an alloy with nanometric crystallite. However, because of the very fast heating rate and the short duration of the plateau, the growth is very limited and the crystallites remain nanometric. The second phase, which is minor (Fig. $4 \mathrm{a}$, inset), can be indexed as a chromium carbide, more specifically the orthorhombic $\mathrm{Cmcm} \mathrm{Cr}_{3} \mathrm{C}_{2}[32,33]$. 
A longitudinal section of HEA-s was characterized by SEM and EDS (Fig. 5). On a low magnification image (Fig. 5a), the border of the pellet exhibits more secondary phases than the core. An area close from the surface of the pellet is magnified on Fig. 5b. Two categories of secondary phases are observed: (i) middle grey precipitates with an irregular shape and a size between approximately 0.5 and $1 \mu \mathrm{m}$, (ii) black and round particles with a diameter smaller than $0.5 \mu \mathrm{m}$. On Fig. $5 \mathrm{~d}$, EDS spectra which were recorded within the matrix, a grey irregular precipitate and a black round precipitate, are plotted respectively in grey, blue and red. It is underlined that EDS does not permit quantitative measurements on such submicronic precipitates. Consequently, a comparative approach was preferred. Compared to the matrix (which is the fcc solid solution), the irregular precipitates are enriched in $\mathrm{C}$ and $\mathrm{Cr}$. Thus, they correspond to the chromium carbides which were detected by XRD (Fig. 4a). The round precipitates are enriched in $\mathrm{O}, \mathrm{Si}, \mathrm{Cr}$ and $\mathrm{Mn}$. Hence, black precipitates are mixed manganese oxides. Those oxides were not visible on XRD diffractograms because their volume fraction is too low or because they are not crystallized enough. In the middle of the pellet (Fig. $5 \mathrm{c}$ ), the same two categories of precipitates can be seen. But their size and volume fraction are significantly smaller than close from the surface, especially for the grey precipitates. The composition of precipitates in the middle or close from the surface is qualitatively the same (Fig. $5 \mathrm{~d}$ and e).

The large volume fraction of carbides close to the surface (ie: close from the mold) and the decreasing gradient of carbides from the surface to the center of the pellet very likely indicate a diffusion of $C$ from the mold towards the pellet during sintering. Concerning the carbides in the core of the pellet, they are probably due to a pre-existing $\mathrm{C}$ contamination in the raw metals. A similar $\mathrm{O}$ contamination and/or an oxidation of the surface of powder grain are also very likely. To summarize, the $C$ and $O$ contaminations in the HEA powders and the $C$ diffusion from the sintering mold lead to the precipitation of $\mathrm{Cr}$ carbides and mixed $\mathrm{Mn}$ oxides. This is in agreement with previous studies on bulk CoCrFeMnNi Cantor alloy in which $\mathrm{Cr}$ carbides [34, 35] and mixed $\mathrm{Cr}$ and $\mathrm{Mn}$ oxides were already observed [36].

Moreover, according to Fig. 5a, the core of the pellet seems to exhibit a heterogeneous distribution of grain size. Grains were further explored by EBSD (Fig. 6). It is recalled that grains are areas of the alloy inside which the crystallographic orientation is constant, and which are delimited by grain boundaries. They should not be confused with powder grains which were studied after milling in the section 3.1. On the band contrast map (Fig. 6a), the main indexed phase is the fcc CoCrFeMnNi while the not indexed black dots, which have a different crystallographic structure from the main phase, correspond to the carbides and oxides which were previously characterized. No specific orientation was detected on the orientation map of the sintered HEA (Fig. 6b). Boundaries were divided into two categories (Fig. 6d): high angle grain boundaries (HAGB) corresponding to a disorientation angle $\theta$ such as $5^{\circ}<\theta<58^{\circ}$ (black); $\Sigma 3$ boundaries for $58^{\circ}<\theta<62^{\circ}$ (red). It is mentioned that no boundary with $\theta>62^{\circ}$ was detected. The $\Sigma 3$ boundaries correspond to annealing twins which were widely observed in bulk CoCrFeMnNi Cantor alloy $[18,37,38]$. They were excluded to determine the size of grains delimited by HAGB. On Fig. $6 c$, those grains are colored according to their surface area. As expected from SEM observations (Fig. 5a), the grain size distribution appears heterogeneous. Some domains contain large grains like in the area 1 (straight line rectangle, Fig. 6) while others contain smaller grains like in area 2 (dashed line rectangle, Fig. 6). The average grain size in areas 1 and 2 were calculated to be respectively $4.2 \pm 2.5 \mu \mathrm{m}$ and $1.3 \pm 0.5 \mu \mathrm{m}$ (Table 3). When comparing Fig. 6a and $\mathrm{c}$ and more precisely areas 1 and 2 , it clearly appears that the domains with small grains contain more oxides and carbides than the one with larger grains. In other words, oxides and/or carbides have limited the growth of grains during sintering. It is underlined that, since oxides and carbides are located close to each other, it is difficult to separate the role of each other. Chen et al. [34] have also reported a grain growth in the CoCrFeMnNi Cantor alloy which was limited by carbides during conventional thermo-mechanical treatments. 


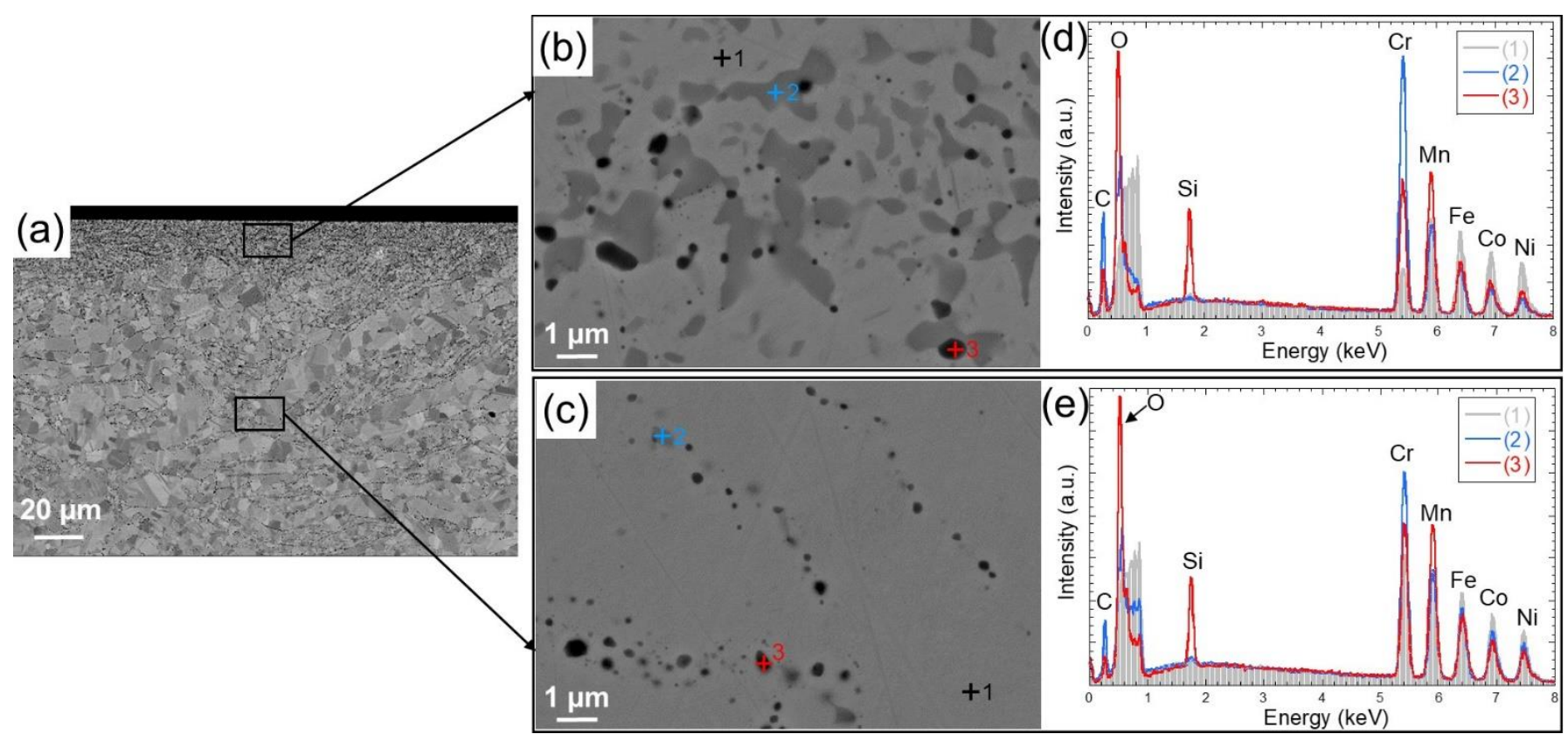

Fig. 5 (Color online): Scanning electron microscope images in backscattered electron (BSE) mode of a CoCrFeMnNi HEA after cryogenic ballmilling, planetary milling and SPS (HEA-s). Image (a) is a cross-section of the pellet, whose surface is on the top of the image. Images (b) and

(c) are zooms of respectively the border and the middle of the densified pellet. (d) and (e) are energy dispersive spectra which were

measured respectively in the border and in the middle of the pellet. The location of each spectrum is indicated by crosses on the corresponding SEM images (b) and (c). (1), (2) and (3) are located respectively on the fcc solid solution, the chromium carbides and the manganese oxides.

a

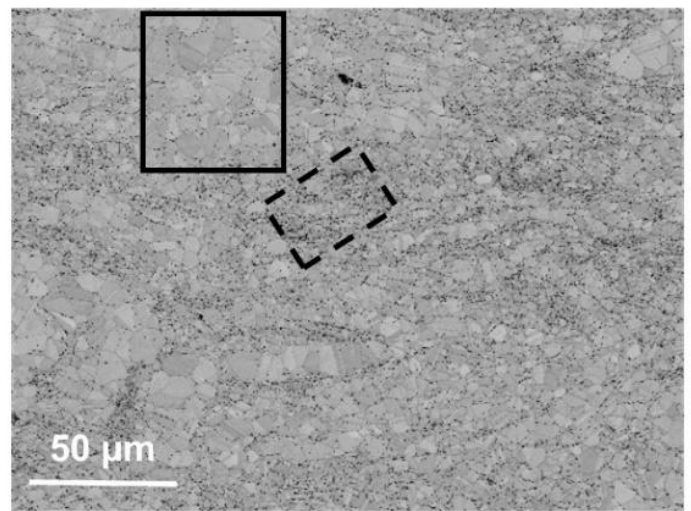

C

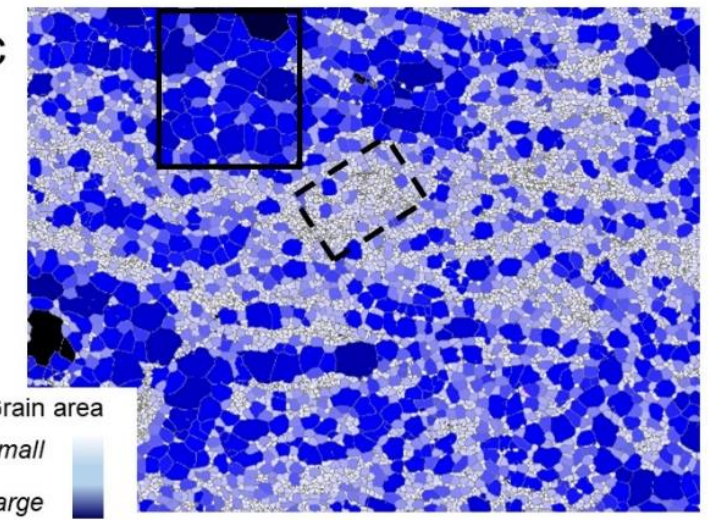

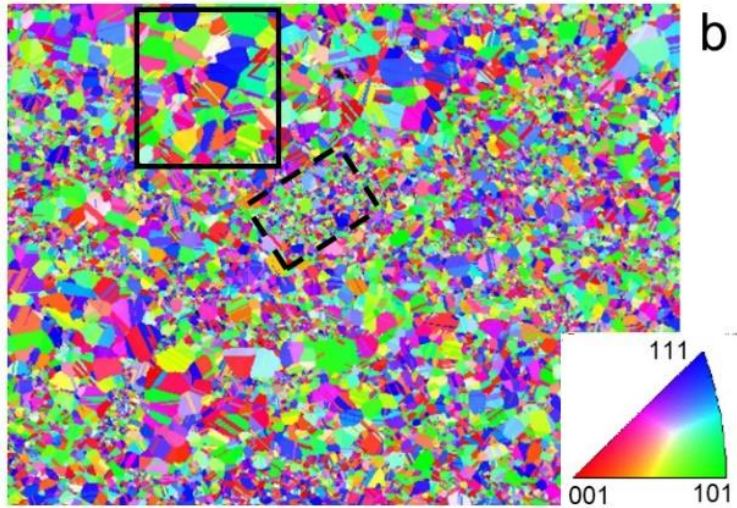

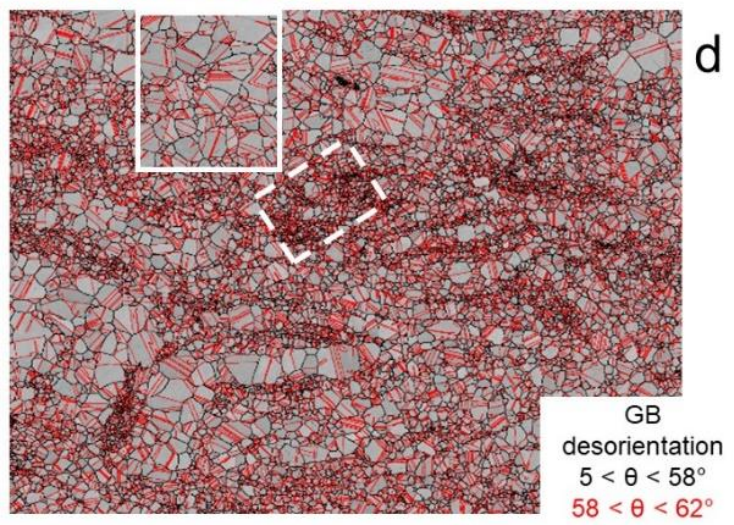

Fig. 6 (Color online): Electron BackScattered Diffraction (EBSD) mapping of a CoCrFeMnNi HEA after cryogenic ball-milling, planetary milling and SPS (HEA-s). (a) Band contrast map. (b) Orientation map with the corresponding standard stereographic triangle (right down corner).

(c) Grain size map. (d) Grain boundary disorientation map (with $\vartheta$ the disorientation angle) superimposed on the band contrast map. The magnification is the same for all four maps. The straight line and dash line rectangles indicate areas with respectively large and small grains. 


\subsection{Nanohardness measurements}

To be able to locally measure the hardness of areas with either large or small grains in the sintered HEA (HEA-s), nanoindentation was chosen. Since areas with (or without) precipitates have small (or large) grains and since the precipitates can be optically observed, it was possible to precisely position the indents (Fig. $7 \mathrm{~b}$ and c). An indent depth of $1 \mu \mathrm{m}$ was chosen as a compromise. Indeed, it is small enough to be in the middle of an area with (or without) precipitates and not to interact with area without (or with) precipitates. It is also large enough to induce a plastic zone larger than a grain and thus to average grain boundary strengthening [39]. For comparison, the hardness in the bulk homogenized CoCrFeMnNi (HEA-b) was also measured. It is underlined that, given the very large grain size $(>300 \mu \mathrm{m})$ of HEA-b compared to the indent depth $(1 \mu \mathrm{m})$, the effect of grain boundary on hardness can be neglected.

Representative loading-unloading curves are plotted on Fig. 7a. A hardness $\mathrm{H}_{1 \mu \mathrm{m}}$ of $2.5 \pm 0.1$ and $3.2 \pm 0.2 \mathrm{GPa}$ was measured in areas with respectively large and small grains while the hardness $\mathrm{H}_{1 \mu \mathrm{m}}$ of HEA-b is $2 \pm 0.05 \mathrm{GPa}$ (Table $3)$. As expected, the combined presence of precipitates and smaller grains leads to a higher hardness in HEA-s with small grains while the hardness of HEA-b, for which there is no grain boundary effect, is the smallest one. The effect of each strengthening mechanism is studied in more details in section 4 . The value of hardness at infinite depth $\mathrm{H}_{0}$, which were extrapolated with the Nix and Gao model (see section Erreur ! Source du renvoi introuvable..), are similarly ranked compared to $\mathrm{H}_{1 \mu \mathrm{m}}$.
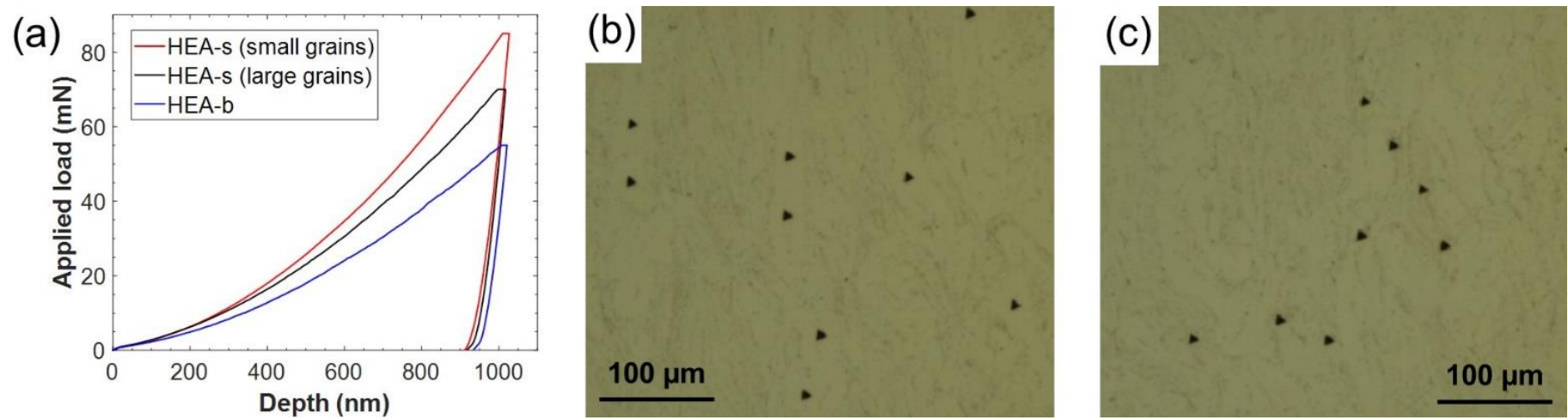

Fig. 7 (Color online): Nanoindentation measurements on a CoCrFeMnNi HEA after cryogenic ball-milling, planetary milling and SPS (HEA-s) and on a bulk COCrFeMnNi HEA (HEA-b). (a) displays representative loading-unloading curves. (b) and (c) are optical images of indents which were performed on HEA-s in areas with respectively large grains and small grains.

Table 3 : Comparison of strengthening mechanism in a CoCrFeMnNi HEA after cryogenic ball-milling, planetary milling and SPS (HEA-s) and in a bulk CoCrFeMnNi HEA (HEA-b). The grain size was measured by EBSD. The hardness at an indentation depth of $1 \mu \mathrm{m} \mathrm{H}_{1 \mu \mathrm{m}}$ was measured by nanoindentation. The hardness at infinite depth $\mathrm{H}_{0}$ was extrapolated from nanoindentation measurements through the Nix and Gao model. The total hardness is decomposed into four strengthening contributions, due to lattice $\left(H_{\text {lattice }}\right)$, solid solution $\left(H_{s s}\right)$, grain

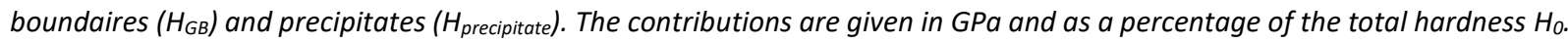

\begin{tabular}{|c|c|c|c|c|c|c|c|}
\hline \multirow{2}{*}{$\begin{array}{c}\text { Sample } \\
\text { description }\end{array}$} & $\begin{array}{c}\text { Grain size } \\
(\mu \mathrm{m})\end{array}$ & $\mathrm{H}_{1 \mu \mathrm{m}}(\mathrm{GPa})$ & $\mathrm{H}_{0}(\mathrm{GPa})$ & \multicolumn{3}{|c|}{ Strengthening contributions } \\
\cline { 5 - 8 } & $>300$ & $2 \pm 0.05$ & $1.64 \pm 0.03$ & $0.75(46 \%)$ & $0.89(54 \%)$ & - & - \\
\hline HEA-b & $\mathrm{H}_{\text {lattice }}(\mathrm{GPa}-$ & $\mathrm{H}_{\mathrm{sS}}(\mathrm{GPa}-\%)$ & $\begin{array}{c}\mathrm{H}_{\mathrm{GB}}(\mathrm{GPa}- \\
\%)\end{array}$ & $\begin{array}{c}\mathrm{H}_{\text {precipitate }} \\
(\mathrm{GPa} \%)\end{array}$ \\
\hline $\begin{array}{c}\text { HEA-s (large } \\
\text { grains) }\end{array}$ & $4.2 \pm 2.5$ & $2.5 \pm 0.1$ & $1.87 \pm 0.09$ & $0.75(40 \%)$ & $0.89(47 \%)$ & $0.26(13 \%)$ & - \\
\hline $\begin{array}{c}\text { HEA-s (small } \\
\text { grains) }\end{array}$ & $1.3 \pm 0.5$ & $3.2 \pm 0.2$ & $2.25 \pm 0.08$ & $0.75(33 \%)$ & $0.89(40 \%)$ & $0.46(20 \%)$ & $0.15(7 \%)$ \\
\hline
\end{tabular}




\section{Discussion}

\subsection{Processing HEA by powder metallurgy}

To assess the potential of powder metallurgy to produce HEA, first, it was intended to produce a CoCrFeMnNi powder by ball-milling. More precisely, to avoid the formation of undesired metastable phases as observed in mechanical alloying of pure metals (see 1.), the alloy was prepared by melting and then was milled. During milling, the fcc phase (i.e.: the single stable phase of the bulk alloy) remains stable as desired.

However, it was shown that planetary milling longer than $0.5 \mathrm{~h}$ has to be avoided for CoCrFeMnNi since it damages the equipment without reducing the powder grain granulometry. To limit this issue, process control agents, such a heptane or toluene, could be considered. However, a $\mathrm{C}$ contamination from those compounds during milling would be very likely. Since CoCrFeMnNi HEA is highly sensitive to $C$ contamination, this would lead to an uncontrolled precipitation of carbides, as was observed in this study, in a small extent (Fig. 5), or in others [34-36]. Milling at a cryogenic temperature, which is commonly used for ductile material, was a mixed success for CoCrFeMnNi. Indeed, the crystallite size was very efficiently reduced to around $10 \mathrm{~nm}$ in only $0.5 \mathrm{~h}$ of milling, without any further increase (Fig. 4). Moreover, after $2 \mathrm{~h}$ of milling, the average granulometry of the powder was micronic (Table 2). However, powder grains were highly anisotropic: they exhibit a shape of "flake" (Fig. 5). Mechanical properties of the CoCrFeMnNi HEA can explain this result. Indeed, it was shown that CoCrFeMnNi is very ductile, even at cryogenic temperature [40]. Thus, during milling, powder grains are mainly plastically deformed and are scarcely fractured, even at cryogenic temperature. To bypass this anisotropy which is due to the intrinsic mechanical properties of the alloy, a two-step milling (i.e.: cryogenic milling followed by a short duration planetary milling) was successfully developed. The milling conditions were chosen based on the previous parametric studies of planetary and cryomilling.

Although the obtained powders were successfully sintered and mechanically tested in the following of this study, this two-step milling has several drawbacks which should be highlighted. First, since it is in two steps, it is more complex. Second, the yielding is low because of the powder sticking during planetary milling. And finally, the granulometry cannot be tuned because the milling conditions have already been optimized to limit the powder sticking. In particular, powder grains smaller than around $80 \mu \mathrm{m}$ would be difficult to obtain. Moreover, it should be underlined that, since many single-phase HEA are very ductile [6], similar unfavorable milling behavior has to be expected. So alternative techniques should be explored. Gas atomization, although more expensive than milling, appears as promising. Indeed, spherical and micronic CoCrFeMnNi powders have already been successfully produced by this technique [31]. To finish, it should be noted that CoCrFeMnNi alloy could be of interest for the socalled "flake powder metallurgy", for which "flake" powder grains are looked for $[41,42]$. This is beyond the scope of this study and thus it was not tested here.

For SPS, appropriate conditions were easily found to fully densify the HEA powder which was obtained by the twostep milling. Indeed, by applying a maximum temperature and pressure of respectively $850^{\circ} \mathrm{C}$ and $100 \mathrm{MPa}$, a volume fraction of porosity lower than $1 \%$ was obtained. Moreover, as wanted, the crystallite growth was limited during SPS and thus a nanometric crystallite size was kept (Fig. 4). During sintering, carbides and oxides precipitate. Parts of the carbides (the ones which are close to the surface) are due to a contamination from the graphite sintering mold. This is a frequently encountered issue in SPS, which is usually solved by grinding the surface of the pellet. The presence of oxides and carbides in the whole pellet depends on the purity of the powder. Thus, the choice and optimization of the process to produce HEA powder, which was discussed above, is of upmost importance.

\subsection{Strengthening contributions}

Yield stress is the combination of the lattice stress, which is sometimes also called the Peierls stress and which is the intrinsic lattice resistance to dislocation motion, plus the strengthening contributions due to the different 
features of the microstructure, such as solute atoms, grain boundaries or precipitates. In a first approximation, which was previously applied for HEA alloys [43], those contributions can be summed up. Following Tabor's work [44], the hardness $\mathrm{H}$ can be similarly described by:

$$
H=H_{\text {lattice }}+H_{S S}+H_{G B}+H_{\text {precipitate }}
$$

where $\mathrm{H}_{\text {lattice, }} \mathrm{H}_{\mathrm{SS}}, \mathrm{H}_{\mathrm{GB}}$ and $\mathrm{H}_{\text {precipitate }}$ are the strengthening contributions of respectively the lattice, the solid solution, the grain boundaries and the precipitates. In the following discussion, only hardnesses which are extrapolated at infinite depth, and which are denoted as $\mathrm{H}_{0}$, will be considered in order to avoid any not comparable size effect. First, for the CoCrFeMnNi HEA, $\mathrm{H}_{\text {lattice }}$ can be assimilated to the hardness of pure $\mathrm{Ni}$. Indeed, $\mathrm{Ni}$ is the only metal of the quinary system which is fcc at room temperature and thus can be artificially considered as the solvent element to which solute (i.e.: $\mathrm{Co}, \mathrm{Cr}$, Fe and $\mathrm{Mn}$ ) are added [30]. Nanoindentation measurements were performed on pure $\mathrm{Ni}$ with millimetric grain size, whose strengthening effect is thus negligible, and the hardness was extrapolated at an infinite depth [45]. Based on those results, $\mathrm{H}_{\text {lattice }}$ was set to $0.75 \mathrm{GPa}$. Second, in the bulk homogenized CoCrFeMnNi sample (HEA-b), grain boundaries are larger than $300 \mu \mathrm{m}$, their effect can be neglected and there is no precipitate. Therefore in this alloy, the solid solution was considered as the only strengthening contribution and this can be used to deduce the contribution part of solid solution strengthening as follows: $H_{s s}=H_{0}(H E A-b)-H_{\text {lattice }}$ and so $\mathrm{H}_{\mathrm{sS}}=0.89 \mathrm{GPa}$. Since all the studied samples are single-phased and have the same chemical composition, the strengthening effect of the solid solution is considered to be the same. Thus the value of $\mathrm{H}_{s s}$ determined for HEA-b was used for all samples. Third, the Hall \& Petch law was applied to determine the grain boundary contribution. For the Hall \& Petch coefficient $\mathrm{k}_{\mathrm{HP}}$, the value previously determined by indentation measurements on a bulk CoCrFeMnNi HEA was used [46]. It gives $H_{G B}=0.677 / \sqrt{ }(d)$ where $d$ is the grain size (in $\mu \mathrm{m}$ ) and where $\mathrm{H}_{\mathrm{GB}}$ is in GPa. Finally, the contribution of precipitates was deducted by subtracting all other contributions from the total hardness: $H_{\text {precipitate }}=H_{0}-\left(H_{\text {lattice }}+H_{S S}+H_{G B}\right)$.

To compute the strengthening contribution of grain boundaries $\mathrm{H}_{\mathrm{GB}}$, first, the possible strengthening effect of crystallites was assessed. An average crystallite size of $32 \pm 13 \mathrm{~nm}$ was measured by XRD in HEA-s. By applying the Hall \& Petch law, $\mathrm{H}_{\mathrm{GB}}$ induced by crystallite would have a value of $3,0 \mathrm{GPa}$. This would lead to a total hardness $\mathrm{H}_{0}$ of 4.6 GPa by adding the lattice and solid solution contributions and by neglecting the precipitates contribution. This is more than twice larger than the measured hardnesses in HEA-s (Table 3 ). On the contrary, $\mathrm{H}_{\mathrm{GB}}$ induced by grains leads to a reasonable contribution of 0.26 or $0.46 \mathrm{GPa}$ for a grain size of respectively $2.5 \pm 0.1$ or $3.2 \pm 0.2 \mu \mathrm{m}$. Consequently, on CoCrFeMnNi HEA, grains which are delimited by high angle grain boundaries are strengthening while crystallites are not. In the following, only grain size is used to calculate $\mathrm{H}_{\mathrm{GB}}$.

The different strengthening contributions were computed for HEA-b and HEA-s in area with large or small grains and are given in Table 3. For all samples, the contribution of the solid solution is the major one (from $54 \%$ to $40 \%$ respectively in HEA-b and HEA-s with small grains). This comes as no surprise since HEA were firstly developed for solid-solution strengthening. The second contribution by order of intensity is the one of grain boundaries which contributes to 13 or $20 \%$ of the total hardness in HEA-s with respectively large and small grains. Although this contribution is not the main one, it is of interest and could be further increased by better controlling the grain size for example by further optimizing SPS conditions. Finally, the direct contribution of precipitates is very limited in this sample $(7 \%)$. The indirect contribution of precipitates was however to limit grain growth and thus to increase grain boundary strengthening.

\section{Conclusion}

Milling and spark plasma sintering were applied to the equimolar CoCrFeMnNi HEA. The obtained powders and pellets were characterized by XRD, SEM coupled with EDS and EBSD as well as nanoindentation. The main results are the following: 
- A CoCrFeMnNi powder which is micronic, approximately spherical and with nanometric crystallites can be produced by a two-step milling (i.e.: cryo-milling and short duration planetary milling) with the bulk alloy as a starting material. The objective of the cryo-milling is to reduce the granulometry while the subsequent planetary milling decreases the shape anisotropy which was induced by the cryo-milling.

- The obtained powder is successfully densified by SPS with a maximum temperature of $850^{\circ} \mathrm{C}$ and an applied pressure of $100 \mathrm{MPa}$ during 4 minutes. The growth of crystallites is very limited.

- The single fcc phase which is present in the starting bulk alloy remains unchanged during milling and SPS. However, due to $\mathrm{C}$ and $\mathrm{O}$ contamination, chromium carbides and mixed manganese oxides precipitate during SPS.

- Processing by milling and sintering of CoCrFeMnNi HEA significantly increases the hardness compared to conventional melting and casting.

- The solid solution and grain boundaries are respectively the first and second strengthening contributions. By limiting grain size, the carbides and oxides have an indirect strengthening effect.

- The grain boundaries strengthening contribution has to be calculated using the size of grains which are delimited by high angle grain boundaries and not the size of crystallite. In other words, grains are mechanically strengthening, contrarily to crystallites.

To conclude, powder metallurgy appears as a promising process for HEA. In the future, to be more efficient, other methods than ball-milling will be used to produce HEA powders. Moreover, SPS conditions will be further optimized with the objective to limit grain growth, and not only crystallite growth. This should further increase grain boundary strengthening.

\section{Acknowledgements}

The authors are grateful to J.-P. Couzinié, J.-M. Joubert and I. Guillot from ICMPE for fruitful discussions. 


\section{References}

1. Yeh, J.W., S.K. Chen, S.J. Lin, J.Y. Gan, T.S. Chin, T.T. Shun, C.H. Tsau, and S.Y. Chang, Nanostructured high-entropy alloys with multiple principal elements: Novel alloy design concepts and outcomes. Advanced Engineering Materials, 2004. 6(5): p. 299-303.

2. Cantor, B., I.T.H. Chang, P. Knight, and A.J.B. Vincent, Microstructural development in equiatomic multicomponent alloys. Materials Science and Engineering: A, 2004. 375-377: p. 213-218.

3. Laurent-Brocq, M., A. Akhatova, L. Perrière, S. Chebini, X. Sauvage, E. Leroy, and Y. Champion, Insights into the phase diagram of the CrMnFeCoNi high entropy alloy. Acta Materialia, 2015. 88(0): p. 355-365.

4. Otto, F., A. Dlouhý, K.G. Pradeep, M. Kuběnová, D. Raabe, G. Eggeler, and E.P. George, Decomposition of the single-phase high-entropy alloy CrMnFeCoNi after prolonged anneals at intermediate temperatures. Acta Materialia, 2016. 112: p. 40-52.

5. Bracq, G., M. Laurent-Brocq, L. Perrière, R. Pirès, J.-M. Joubert, and I. Guillot, The fcc solid solution stability in the Co-Cr-Fe-Mn-Ni multi-component system. Acta Materialia, 2017. 128: p. 327-336.

6. Ye, Y.F., Q. Wang, J. Lu, C.T. Liu, and Y. Yang, High-entropy alloy: challenges and prospects. Materials Today, 2016. 19(6): p. 349-362.

7. Gludovatz, B., A. Hohenwarter, D. Catoor, E.H. Chang, E.P. George, and R.O. Ritchie, A fracture-resistant highentropy alloy for cryogenic applications. Science, 2014. 345(6201): p. 1153-1158.

8. Zhang, Y., Y.J. Zhou, J.P. Lin, G.L. Chen, and P.K. Liaw, Solid-solution phase formation rules for multi-component alloys. Advanced Engineering Materials, 2008. 10(6): p. 534-538.

9. He, J.Y., H. Wang, H.L. Huang, X.D. Xu, M.W. Chen, Y. Wu, X.J. Liu, T.G. Nieh, K. An, and Z.P. Lu, A precipitationhardened high-entropy alloy with outstanding tensile properties. Acta Materialia, 2016. 102: p. 187-196.

10. Gwalani, B., V. Soni, M. Lee, S.A. Mantri, Y. Ren, and R. Banerjee, Optimizing the coupled effects of Hall-Petch and precipitation strengthening in a Al0.3CoCrFeNi high entropy alloy. Materials \& Design, 2017. 121: p. 254-260.

11. Lilensten, L., J.-P. Couzinié, J. Bourgon, L. Perrière, G. Dirras, F. Prima, and I. Guillot, Design and tensile properties of a bcc Ti-rich high-entropy alloy with transformation-induced plasticity. Materials Research Letters, 2016: p. 1-7.

12. Li, Z.M., K.G. Pradeep, Y. Deng, D. Raabe, and C.C. Tasan, Metastable high-entropy dual-phase alloys overcome the strength-ductility trade-off. Nature, 2016. 534(7606): p. 227.

13. Sun, S.J., Y.Z. Tian, H.R. Lin, X.G. Dong, Y.H. Wang, Z.J. Zhang, and Z.F. Zhang, Enhanced strength and ductility of bulk CoCrFeMnNi high entropy alloy having fully recrystallized ultrafine-grained structure. Materials \& Design, 2017. 133(Supplement C): p. 122-127.

14. Wu, Z., H. Bei, F. Otto, G.M. Pharr, and E.P. George, Recovery, recrystallization, grain growth and phase stability of a family of FCC-structured multi-component equiatomic solid solution alloys. Intermetallics, 2014. 46(0): p. 131-140.

15. Senkov, O.N. and S.L. Semiatin, Microstructure and properties of a refractory high-entropy alloy after cold working. Journal of Alloys and Compounds, 2015. 649: p. 1110-1123.

16. Lilensten, L., J.P. Couzinié, L. Perrière, A. Hocini, C. Keller, G. Dirras, and I. Guillot, Study of a bcc multi-principal element alloy: Tensile and simple shear properties and underlying deformation mechanisms. Acta Materialia, 2018. 142(Supplement C): p. 131-141.

17. Schuh, B., B. Völker, J. Todt, N. Schell, L. Perrière, J. Li, J.P. Couzinié, and A. Hohenwarter, Thermodynamic instability of a nanocrystalline, single-phase TiZrNbHfTa alloy and its impact on the mechanical properties. Acta Materialia, 2018. 142(Supplement C): p. 201-212.

18. Laplanche, G., O. Horst, F. Otto, G. Eggeler, and E.P. George, Microstructural evolution of a CoCrFeMnNi highentropy alloy after swaging and annealing. Journal of Alloys and Compounds, 2015. 647: p. 548-557. 
19. Varalakshmi, S., M. Kamaraj, and B.S. Murty, Synthesis and characterization of nanocrystalline AlFeTiCrZnCu high entropy solid solution by mechanical alloying. Journal of Alloys and Compounds, 2008. 460(1-2): p. 253-257.

20. Zhang, K.B., Z.Y. Fu, J.Y. Zhang, J. Shi, W.M. Wang, H. Wang, Y.C. Wang, and Q.J. Zhang, Nanocrystalline CoCrFeNiCuAl high-entropy solid solution synthesized by mechanical alloying. Journal of Alloys and Compounds, 2009. 485(1-2): p. L31-L34.

21. Qiu, X.-W., Microstructure and properties of AlCrFeNiCoCu high entropy alloy prepared by powder metallurgy. Journal of Alloys and Compounds, 2013. 555(0): p. 246-249.

22. Waseem, O.A. and H.J. Ryu, Powder Metallurgy Processing of a WxTaTiVCr High-Entropy Alloy and Its Derivative Alloys for Fusion Material Applications. Scientific Reports, 2017. 7(1): p. 1926.

23. Fu, Z., B.E. Macdonald, D. Zhang, B. Wu, W. Chen, J. Ivanisenko, H. Hahn, and E.J. Lavernia, Fcc nanostructured TiFeCoNi alloy with multi-scale grains and enhanced plasticity. Scripta Materialia, 2018. 143(Supplement C): p. 108-112.

24. Ji, W., W. Wang, H. Wang, J. Zhang, Y. Wang, F. Zhang, and Z. Fu, Alloying behavior and novel properties of CoCrFeNiMn high-entropy alloy fabricated by mechanical alloying and spark plasma sintering. Intermetallics, 2015. 56: p. 24-27.

25. Cheng, H., Y.-C. Xie, Q.-H. Tang, C. Rao, and P.-Q. Dai, Microstructure and mechanical properties of FeCoCrNiMn high-entropy alloy produced by mechanical alloying and vacuum hot pressing sintering. Transactions of Nonferrous Metals Society of China, 2018. 28(7): p. 1360-1367.

26. Mane, R.B., R. Y, and B.B. Panigrahi, Sintering mechanism of CoCrFeMnNi high-entropy alloy powders. Powder Metallurgy, 2018. 61(2): p. 131-138.

27. Shivam, V., J. Basu, Y. Shadangi, M.K. Singh, and N.K. Mukhopadhyay, Mechano-chemical synthesis, thermal stability and phase evolution in AlCoCrFeNiMn high entropy alloy. Journal of Alloys and Compounds, 2018. 757: p. 87-97.

28. Oliver, W.C. and G.M. Pharr, Measurement of hardness and elastic modulus by instrumented indentation: Advances in understanding and refinements to methodology. Journal of Materials Research, 2004. 19(01): p. 3-20.

29. Nix, W.D. and H. Gao, Indentation size effects in crystalline materials: A law for strain gradient plasticity. Journal of the Mechanics and Physics of Solids, 1998. 46(3): p. 411-425.

30. Laurent-Brocq, M., L. Perrière, R. Pirès, F. Prima, P. Vermaut, and Y. Champion, From diluted solid solutions to high entropy alloys: On the evolution of properties with composition of multi-components alloys. Materials Science and Engineering: A, 2017. 696: p. 228-235.

31. Liu, Y., J. Wang, Q. Fang, B. Liu, Y. Wu, and S. Chen, Preparation of superfine-grained high entropy alloy by spark plasma sintering gas atomized powder. Intermetallics, 2016. 68: p. 16-22.

32. Jain, A., S.P. Ong, G. Hautier, W. Chen, W.D. Richards, S. Dacek, S. Cholia, D. Gunter, D. Skinner, G. Ceder, and K.A. Persson, The Materials Project: A materials genome approach to accelerating materials innovation. APL Materials, 2013. 1(1): p. 011002.

33. Project, M., Cr3C2 Cmcm, orthorombic. https://materialsproject.org/materials/mp-570112//Consulted on 13/06/2018).

34. Cheng, H., H.Y. Wang, Y.C. Xie, Q.H. Tang, and P.Q. Dai, Controllable fabrication of a carbide-containing FeCoCrNiMn high-entropy alloy: microstructure and mechanical properties. Materials Science and Technology, 2017. 33(17): p. 2032-2039.

35. Laurent-Brocq, M., X. Sauvage, A. Akhatova, L. Perrière, E. Leroy, and Y. Champion, Precipitation and strength of carbonitrides in a CrMnFeCoNi high entropy alloy. Advanced Engineering Materials, 2017.

36. Choi, N., K.R. Lim, Y.S. Na, U. Glatzel, and J.H. Park, Characterization of non-metallic inclusions and their influence on the mechanical properties of a FCC single-phase high-entropy alloy. Journal of Alloys and Compounds, 2018. 763: p. 546-557. 
37. Bhattacharjee, P.P., G.D. Sathiaraj, M. Zaid, J.R. Gatti, C. Lee, C.-W. Tsai, and J.-W. Yeh, Microstructure and texture evolution during annealing of equiatomic CoCrFeMnNi high-entropy alloy. Journal of Alloys and Compounds, 2014. 587(0): p. 544-552.

38. Otto, F., A. Dlouhý, C. Somsen, H. Bei, G. Eggeler, and E.P. George, The influences of temperature and microstructure on the tensile properties of a CoCrFeMnNi high-entropy alloy. Acta Materialia, 2013. 61(15): p. 5743-5755.

39. Yang, B. and H. Vehoff, Dependence of nanohardness upon indentation size and grain size -A local examination of the interaction between dislocations and grain boundaries. Acta Materialia, 2007. 55(3): p. 849-856.

40. Laplanche, G., A. Kostka, O.M. Horst, G. Eggeler, and E.P. George, Microstructure evolution and critical stress for twinning in the CrMnFeCoNi high-entropy alloy. Acta Materialia, 2016. 118: p. 152-163.

41. Fan, G., R. Xu, Z. Tan, D. Zhang, and Z. Li, Development of Flake Powder Metallurgy in Fabricating Metal Matrix Composites: A Review. Acta Metallurgica Sinica (English Letters), 2014. 27(5): p. 806-815.

42. Jiang, L., Z. Li, G. Fan, and D. Zhang, A flake powder metallurgy approach to Al2O3/Al biomimetic nanolaminated composites with enhanced ductility. Scripta Materialia, 2011. 65(5): p. 412-415.

43. Wu, Z., H. Bei, G.M. Pharr, and E.P. George, Temperature dependence of the mechanical properties of equiatomic solid solution alloys with face-centered cubic crystal structures. Acta Materialia, 2014. 81(0): p. 428-441.

44. Tabor, D., Hardness of metals. 1951, Oxford: Clarendon Press.

45. Durst, K., O. Franke, A. Böhner, and M. Göken, Indentation size effect in Ni-Fe solid solutions. Acta Materialia, 2007. 55(20): p. 6825-6833.

46. Liu, W.H., Y. Wu, J.Y. He, T.G. Nieh, and Z.P. Lu, Grain growth and the Hall-Petch relationship in a high-entropy FeCrNiCoMn alloy. Scripta Materialia, 2013. 68(7): p. 526-529. 